San Jose State University

SJSU ScholarWorks

Master's Theses

Master's Theses and Graduate Research

1995

\title{
Spatial and temporal sensitivity of the purple sea urchin (Strongylocentrotus purpuratus) to zinc
}

Bryn M. Phillips

San Jose State University

Follow this and additional works at: https://scholarworks.sjsu.edu/etd_theses

\section{Recommended Citation}

Phillips, Bryn M., "Spatial and temporal sensitivity of the purple sea urchin (Strongylocentrotus purpuratus) to zinc" (1995). Master's Theses. 1173.

DOI: https://doi.org/10.31979/etd.sys5-ewh2

https://scholarworks.sjsu.edu/etd_theses/1173

This Thesis is brought to you for free and open access by the Master's Theses and Graduate Research at SJSU ScholarWorks. It has been accepted for inclusion in Master's Theses by an authorized administrator of SJSU ScholarWorks. For more information, please contact scholarworks@sjsu.edu. 


\section{INFORMATION TO USERS}

This manuscript has been reproduced from the microfilm master. UMI films the text directly from the original or copy submitted. Thus, some thesis and dissertation copies are in typewriter face, while others may be from any type of computer printer.

The quality of this reproduction is dependent upon the quality of the copy submitted. Broken or indistinct print, colored or poor quality illustrations and photographs, print bleedthrough, substandard margins, and improper alignment can adversely affect reproduction.

In the unlikely, event that the author did not send UMI a complete manuscript and there are missing pages, these will be noted. Also, if unauthorized copyright material had to be removed, a note will indicate the deletion.

Oversize materials (e.g., maps, drawings, charts) are reproduced by sectioning the original, beginning at the upper left-hand comer and contimuing from left to right in equal sections with small overlaps. Each original is also photographed in one exposure and is included in reduced form at the back of the book.

Photographs included in the original manuscript have been reproduced xerographically in this copy. Higher quality $6^{n} \times 9^{n}$ black and white photographic prints are available for any photographs or illustrations appearing in this copy for an additional charge. Contact UMI directly to order.

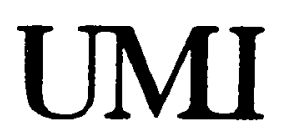

A Bell \& Howell information Company 300 North Zeeb Road. Ann Arbor. MI 48106-1346 USA 



\title{
SPATIAL AND TEMPORAL SENSITIVITY OF THE PURPLE SEA URCHIN (STRONGYLOCENTROTUS PURPURATUS) TO ZINC
}

\author{
A Thesis Presented to \\ The Faculty of the Department of Biology \\ San Jose State University
}

\author{
In Partial Fulfillment \\ of the Requirements for the Degree \\ Master of Science
}

By

Bryn M. Phillips

December 1995 
UMI Number: 1377264

UMI Microform 1377264

Copyright 1996, by UMI Company. All rights reserved.

This microform edition is protected against unauthorized copying under Title 17, United States Code.

\section{UMI}

300 North Zeeb Road

Ann Arbor, MI 48103 
(C) 1995

Bryn M. Phillips

ALL RIGHTS RESERVED 


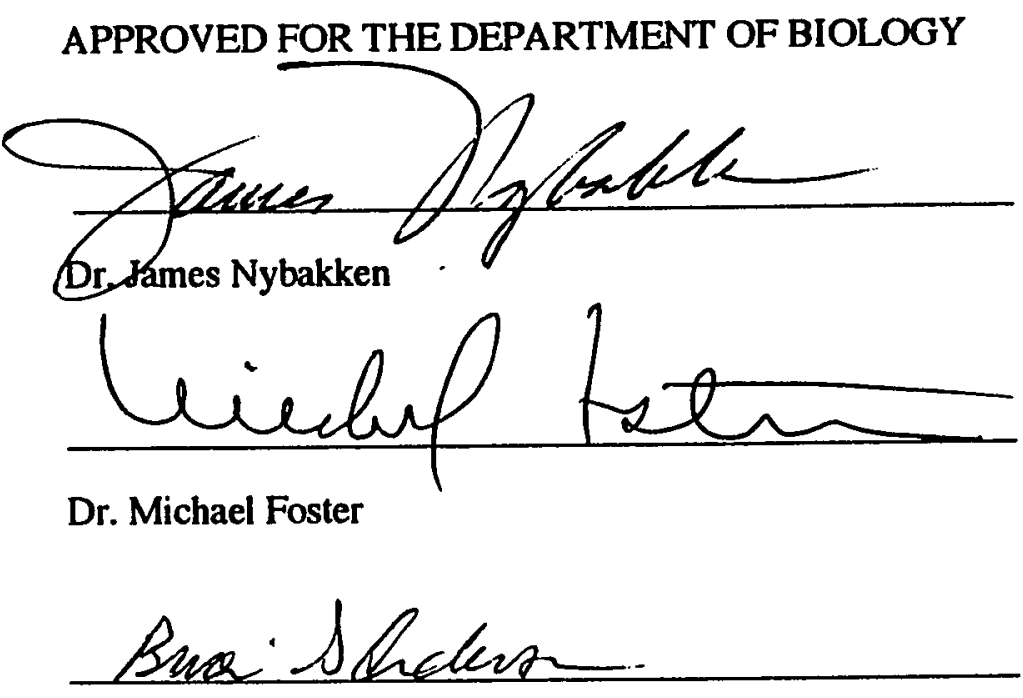

Brian Anderson

APPROVED FOR THE UNIVERSITY

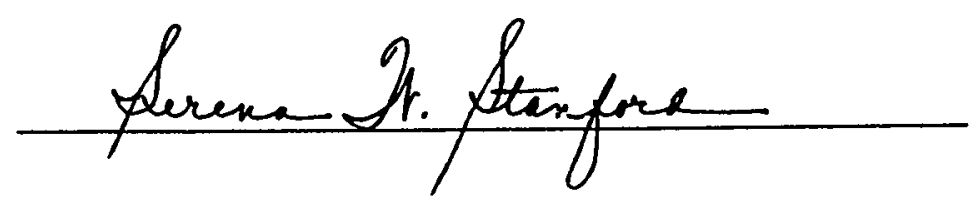




\section{ABSTRACT \\ SPATIAL AND TEMPORAL SENSITIVITY OF THE PURPLE SEA URCHIN (STRONGYLOCENTROTUS PURPURATUS) TO ZINC}

By Bryn M. Phillips

Purple sea urchins (Strongylocentrotus purpuratus) are commonly used in toxicity tests on the west coast for National Pollutant Discharge Elimination System (NPDES) permit monitoring and other pollution assessment applications. Purple sea urchins were kept in spawning condition in the laboratory for use in fertilization and larval development experiments designed to assess temporal variability in response to zinc sulfate over a year-long period. The results of these tests were compared to those using gametes from a wild population. Fertilization and larval development tests were also conducted comparing wild urchins from three geographically isolated groups on the west coast. Fertilization tests for the temporal study produced variable EC50's ranging from $4.1 \mathrm{mg} / \mathrm{l}$ to $>100 \mu \mathrm{g} / \mathrm{l}$ zinc. Larval development tests consistently resulted in EC50's averaging $107.4 \pm 21.9 \mu \mathrm{g} / \mathrm{l}$ zinc $(\mathrm{CV}=20.8 \%)$ for laboratory urchins and $97.2 \pm 19.2 \mu \mathrm{g} / \mathrm{l}$ zinc $(\mathrm{CV}=19.4 \%)$ for wild urchins. Interpopulation larval development results were not significantly different. Fertilization variability was examined in terms of sperm concentration and sperm collection method during two seasons. Reduced variability was found in tests conducted in March, 1995 with dry sperm collection, but increased again in tests conducted in June, 1995 regardless of method, suggesting seasonal temperature effects might cause variability. Larval development tests demonstrated low variability and consistent results in year-round testing while fertilization tests might not be suitable for testing throughout the year. 


\section{ACKNOWLEDGMENTS}

The author thanks the following individuals for their contributions to this study: Brian Anderson and John Hunt for being my mentors before, during and after the study; Lisa Weetman, Michelle Hester, and the rest of the personnel at Granite Canyon for their constant support; and Marilyn Schwartz and Barry Snyder for convincing me to go to graduate school. Rusty Fairy, John Goetzel, and the crew at Musselwatch and Bay Protection need to be thanked for their technical support and sense of humor. Dr James Nybakken and Dr. Michael Foster advised me on experimental design and thoroughly edited the manuscript.

This study was supported by the University of California, Santa Cruz, the Marine Pollution Studies Laboratory, and the Packard Foundation. 


\section{TABLE OF CONTENTS}

$\begin{array}{ll}\text { Copyright } & \text { ii }\end{array}$

Signature Page iii

Abstract iv

Acknowledgments $\quad \mathrm{v}$

List of Figures vii

Introduction 1

Methods 3

$\begin{array}{ll}\text { Results } & 7\end{array}$

$\begin{array}{ll}\text { Discussion } & 10\end{array}$

$\begin{array}{ll}\text { References } & 16\end{array}$

$\begin{array}{ll}\text { Figures } & 21\end{array}$ 


\section{LIST OF FIGURES}

Figure Page

1) Mean gonad index of laboratory and field urchins plotted 21 with day length against time, mean spawning success of urchin groups versus time, and mean temperature of laboratory and field collection site versus time.

2) Mean egg diameter for laboratory and field collected urchins relative to time.

3) Mean egg diameter of urchins collected from three geographic locations.

4) Mean EC50 from larval development tests performed on laboratory maintained and field collected urchins versus time.

5) Mean EC50 from larval development tests performed on urchins from three geographically isolated locations.

6) Mean EC50 from fertilization tests performed on laboratory maintained and field collected urchins versus time.

7) Mean fertilization EC50s from tests comparing sperm collection methods and sperm to egg ratios. 


\section{INTRODUCTION}

The purple sea urchin (Strongylocentrotus purpuratus) is a common lower intertidal inhabitant ranging from Alaska to Southern California (Morris et al. 1980). The purple urchin can play an important role in the structure of kelp forests and other subtidal communities because of its population dynamics and feeding (Pearse and Hines 1987). Sea urchins are sensitive to a variety of ions and toxicants (Sano and Mohri 1976, Mitsunaga and Yasumasu 1984), and are readily available from field collection and commercial suppliers making it a widely used test organism (reviewed by Bay et al. 1993). Such tests with the purple urchin commonly use two early life history stages: sperm exposure tests with a fertilization endpoint and a larval development test that measures larval survival and development.

Historically, bioassays of municipal wastewater discharged into marine environments used freshwater fish in 96-hour toxicity tests (Oshida et al. 1981). It was demonstrated, however, that this practice was not rigorous enough to monitor wastewater. Kobayashi (1972) determined that toxicity to sensitive life stages of marine organisms such as sea urchins can still occur at the discharge point, and Oshida et al. (1981) demonstrated toxic effects of wastewater on purple sea urchin fertilization, survival and development. Only recently have toxicity tests with marine species been required by the State of California. The sea urchin fertilization test was incorporated into the State Water Resources Control Board's California Ocean Plan in 1990, and the larval development test is expected to be added inn 1995.

The use of echinoderm early life-history tests in pollution monitoring have been thoroughly reviewed (Dinnel et al. 1988, Nacci et al. 1990, Bay et al. 1993). The fertilization test has applications for short-term testing because it can be completed and analyzed within a single day. Short-term exposure of sperm to a toxicant and a subsequent measure of fertilized eggs is convenient for the measurement of transient 
toxicity of volatile compounds. Urchin sperm also have a high tolerance to ammonia, a naturally occurring toxicant that can produce a false positive in test results. The fertilization test has recently been used in the study of sediment toxicity (Burgess et al. 1993) and in toxicity identification evaluations (Ankley et al. 1991).

The embryo-larval development test has been widely used to characterize a variety or toxicants and has recently been used to study sediment elutriate toxicity (Meador et al. 1990), interstitial water toxicity (Carr and Chapman 1990), cytological and cytogenetic effects (Hose 1985, Long et al. 1990), and recently been used to assess toxicity at the sediment-water interface (Anderson et al. 199X). Bay et al. (1983) have also correlated the synthesis of echinochrome in urchin larvae with survival and development endpoints to simplify larval development test termination.

Purple urchins spawn in the late fall and winter with small within-year variations. Their spawning cycle is controlled by photoperiod; gametogenesis is inhibited by the exposure to longer days (Pearse et al. 1986a). The presence of a yearly cycle in the wild prohibits most laboratories from performing year-round toxicity tests. It is common practice to alternate between summer and winter spawning echinoderm species (urchin and sand dollar, Dendraster excentricus) to facilitate year-round monitoring of wastewater (Bay et al. 1993). Problems with this practice include variability in sensitivity among different echinoderm species (Dinnel et al. 1989), as well as periods at the extremes of the spawning cycles in which neither animal is spawning. Increasing the variability of the test procedure increases the chances of producing a false positive or negative test result. Low variability is an important attribute in any successful toxicity test.

It has been suggested that purple urchins can be used for testing year-round by keeping animals in spawning condition in the laboratory (Bay et al. 1993). Urchins have been maintained in spawning condition year-round by being kept under fall-winter 
photoperiods (Pearse et al. 1986a), and by holding them at low temperatures in darkness (Leahy et al. 1978). Bay et al. (1993) state there is low temporal variation in toxicity tests using laboratory-conditioned animals, especially relative to tests using field populations near the limits of their spawning season. Using laboratory maintained urchins could also minimize variability produced by alternating test species and from differences due to variation among field collection sites. Anomalies in field conditions such as extreme wave activity, storm runoff, reduced food availability, or disease could render animals unusable and cause a laboratory to collect animals from another site or purchase animals from a remote supplier. However, there have been no studies comparing the sensitivity of laboratory maintained purple urchins to different purple urchin populations.

The objective of this study was to evaluate the relative variation in spatial and temporal sensitivity of several groups of purple urchins in order to determine their effectiveness as a year-round toxicity test organism. Temporal variation in sensitivity of a wild group of urchins was compared with the sensitivity of a laboratory-conditioned group using a zinc reference toxicant in sperm fertilization and larval development toxicity tests. Temporal variation in gonadal indices, egg sizes, and spawning success were also compared between the two groups. To determine differences among geographically isolated groups of urchins, spatial variation in sensitivity was compared among animals collected from three different populations in the field.

\section{METHODS}

The laboratory urchin population was collected from a site near Granite Creek, Carmel, California during the early 1993 spawning season (January-February). The site was a protected pool filled by wave action and isolated from potential urchin predators. Shallow and deep areas were cobble fields with sparse macroalgae, and areas of 
intermediate depth were coralline mats and urchin barrens. The laboratory population was maintained at the Marine Pollution Studies Laboratory at Granite Canyon (MPSL) in total darkness and at ambient sea water temperature for the duration of the study. Animals were fed fresh giant kelp (Macrocystis) weekly, and tanks were cleaned at the time of feeding.

Three times during each testing period 15 to 25 urchins were collected from the Granite Creek population for toxicity tests. Two week testing periods, separated by approximately four week intervals, were conducted from early February 1994 to mid March 1995. Collected animals were held for 24 hours in the laboratory and then spawned for testing. Gametes and larvae were tested for sensitivity to the reference toxicant zinc sulfate. The larval development test followed an MPSL in-house protocol modeled after ASTM (1995) whereby embryos are exposed to zinc for 96 hours and their development is evaluated as the test endpoint. Criteria for normal development is the formation of skeletal rods that are greater than half the length of the larva and the development of a three part gut. The fertilization bioassay followed Dinnel et al. (1987). Sperm are exposed to zinc for one hour before eggs are added for a 20 minute fertilization period. After being fixed with formalin, eggs are examined for fertilization membranes and percent fertilization determined. Water temperature for both tests was $15^{\circ} \mathrm{C}$. Based on previous fertilization tests conducted at MPSL, a 500:1 sperm to egg ratio, wet sperm collection (rinsing the gametes from the urchin with a squirt bottle), and an acceptability criterion of $50 \%$ control fertilization were used. Urchin larvae were exposed to five laboratory replicates of $0,18,32,56,100,180$, and $320 \mu \mathrm{g} / \mathrm{l}$ total zinc, and the fertilization test used five replicates of $0,3.2,5.6,10,18,32,56$, and $100 \mu \mathrm{g} / \mathrm{l}$ total zinc. Identical tests were performed simultaneously using urchins from laboratory and field populations. After testing was completed, the spawned urchins were placed in separate 
tanks in the laboratory. Laboratory urchins were kept and field collected urchins were returned to the collection site at the end of the study.

Zinc was chosen as a reference toxicant because it is a major constituent in municipal sewage effluent (Schafer 1990), and its effects in sea urchin toxicity tests are apparent. Zinc is known to affect sand dollar larvae by causing exogastrulation and retarded spicule growth (Rulon 1957). The specific physiological mechanism of zinc toxicity to sperm is not known, but may include reduced motility. Zinc is known to play an important role in cell membrane stability, and increased levels of the metal can compete with calcium accumulation by the mitochondria during anaerobic ATP production (Viarengo 1985)

The concentration of zinc that affected 50\% of the test organisms (EC50's) in the fertilization and development tests were calculated using a trimmed Spearman-Karber analysis (Hamilton et al. 1977). After determining the proportion of normal larvae or the proportion of fertilized eggs per replicate, the proportions were transformed using the arc sine of the square root. EC50's were computed from transformed data using the TOXIS statistical program (Ecoanalysis, Ojai, California). The Spearman-Karber test creates a dose-response curve and estimates what concentration of zinc affected $50 \%$ of the organisms. This method was chosen because it is more robust than the probit or logit methods when working with toxicity test data that might contain anomalies. The Spearman-Karber method will not estimate an EC50 if 50\% of the organisms were not affected by the concentrations used. In this instance, a less robust probit analysis was used to extrapolate the EC50 using TOXIS. Three EC50's from three separate toxicity tests were produced for each set of urchins during each collection period. Each EC50 value was treated as a replicate, and was used to compare laboratory and field collected urchins using two factor analysis of variance with testing period and population as the 
factors (Zar 1974). Variance homogeneity was confirmed using Levene's test before the performance of all analysis of variance tests (Milliken and Johnson 1984)

The reproductive season of field and laboratory populations was determined using a measure of gonadal index (described by Gonor 1972) and spawning success. Ten urchins with test diameters $40-50 \mathrm{~mm}$ from each population were used per collection period for reproductive monitoring. Gonads were removed from the urchins, and sex determined from extruded gametes. The gonads, viscera, and test were dried to constant weight and weighed to the nearest milligram. The gonad index was calculated as:

$$
\frac{\text { dry weight gonads }}{\text { total dry weight }} \times 100
$$

Spawning success was determined at the beginning of toxicity tests by recording the number of spawning and non-spawning urchins after injection $0.5 \mathrm{ml}$ of $0.5 \mathrm{M}$ potassium chloride into ten animals. Gonadal indices and spawning success from the two populations were compared using a two factor analysis of variance with group and testing period as the factors. Gonad indices and spawning success were also compared with day length and water temperature using Spearman Rank correlations (Zar 1974).

Egg diameters were measured from each testing period to determine if differences existed between groups and among testing periods. Ten eggs were measured from the preserved samples of the first fertilization test of each test period. Egg sizes were not significantly affected by the formalin preservative. Eggs were measured to the nearest five microns using an Olympus BH-2 microscope with ocular micrometer. Significant differences were determined using a two factor analysis of variance followed by a Tukey test to determine significant differences among the means.

The sensitivities of three geographically defined populations of purple urchins were compared at the peak of the reproductive season in March. Urchins were acquired from suppliers in San Diego, California and Newport, Oregon. These animals were tested 
for zinc sensitivity using fertilization and development toxicity tests described previously. Tests on each population were conducted three times on succesive days. Results were compared to the Granite Creek population in a single factor analysis of variance. Egg sizes were also compared for the spatial study. Thirty eggs from each population were measured as above and compared using a single factor analysis of variance.

Laboratory and field water temperature were measured at the time of collection. Day length was noted weekly as the time from sunrise to sunset in Carmel, California. Water quality parameters including $\mathrm{pH}$ and dissolved oxygen were recorded throughout the study. Zinc reference toxicant stock concentrations were verified for every group of tests conducted using flame spectroscopy.

\section{RESULTS}

The gonads of the wild Granite Creek urchin group were consistently smaller than the laboratory group (Fig la), yet enough gametes were obtained for testing during each testing period. The gonad indices of the wild urchin group exhibited the predictable trend of decreasing in the summer months and increasing in the winter, as did the laboratory to a lesser degree. Mean gonad indices of both groups were significantly correlated $\left(r_{s}=0.800, p<0.02, n=9\right)$. Two factor analysis of variance on square root transformed data found significant differences between the two urchin groups $(F=213.329, p<0.001)$, among testing periods $(F=18.685, p<0.001)$, and interactive significance $(F=6.004$, $\mathrm{p}<0.001)$. Results of Tukey tests indicated that laboratory gonads were significantly larger in all testing periods but the eighth, which began at the end December, 1994 $(\mathrm{p}<0.05)$. Within groups, the gonads were significantly larger in the winter months. Correlations between gonad sizes and day length were significantly negative $\left(r_{s}=-0.867\right.$, $\mathrm{p}<0.005 \mathrm{n}=9$ for lab indices; $\mathrm{r}_{\mathrm{s}}=-0.700, \mathrm{p}<0.05, \mathrm{n}=9$ for field indices ). 
Although both groups of urchins spawned well over the entire year (Fig. 1b), fewer individuals spawned from the field collected group and the two groups were significantly different from one another (two factor ANOVA; $F=3.458, p<0.01$ for groups; $\mathrm{F}=13.1, \mathrm{p}<0.001$ for periods). Qualitative observations indicated fewer gametes during the summer months when gonad size of the wild urchin group was smaller. The spawning success of both urchin groups was positively correlated $\left(r_{s}=0.852, p<0.02\right.$, $\mathrm{n}=8$ ). There were no significant differences between temperatures in the laboratory and the field (Fig. 1c).

There were no significant differences in egg size between urchin groups or among testing periods (Fig. 2; Kruskal-Wallis test; $\mathrm{X}^{2}=-2.21, \mathrm{p}>0.10$ for groups; $\mathrm{X}^{2}=0.269$, p $>0.999$ for periods). Egg diameters from wild urchins were slightly larger on average than laboratory animals $(76.7 \mu \pm 3.5$ vs. $75.6 \mu \pm 1.6)$, and the variability throughout the year was low with a $2.2 \%$ coefficient of variation for lab eggs and $4.6 \%$ for the wild urchins. Measurements made during the spatial study showed eggs from San Diego to be significantly larger than eggs from central California and Newport, OR (Fig. 3; analysis of variance; $F=8.907, p=0.0003$ ).

Purple urchin larvae responded consistently to zinc throughout the year (Fig. 4). Larval development tests using laboratory maintained urchins produced a mean EC50 of $107.4 \pm 21.9 \mu \mathrm{g} / \mathrm{l}$ zinc; the wild urchin group produced a mean EC50 of $97.2 \pm 19.2 \mu \mathrm{g} / \mathrm{l}$ zinc. Coefficients of variation were $20.4 \%$ and $19.8 \%$, respectively. Chemical confirmation of stock solutions produced a coefficient of variation of $3.1 \%$, therefore no adjustments were made to the nominal concentrations. Two factor analysis of variance showed no significant difference between urchin groups or among test periods $(F=3.112$, $\mathrm{p}=0.0872$ for urchin groups; $F=1.546, \mathrm{p}=0.1876$ for test periods). Single factor analysis of variance produced similar results for the spatial study. Though there appears to be a trend of increasing sensitivity from northern to southern groups, there were no 
significant differences in development when tested simultaneously (Fig. 5; $F=2.302$, $\mathrm{p}=0.1812$ ). There were also no significant differences when the EC50's of the three populations were compared to EC50's generated throughout the year in the temporal study.

Fertilization tests resulted in variable EC50's ranging from 4.1 to $>100 \mu \mathrm{g} / \mathrm{l}$ zinc (Fig. 6). The use of a single sperm to egg ratio and wet sperm collection methods in the fertilization tests may have caused the extensive variability. Coefficients of variation were $86.5 \%$ for the laboratory group and $78.2 \%$ for the wild group. Because of high variability, no statistical comparisons were made.

To investigate sources of variability in the fertilization tests, experiments were done in March and June, 1995 to examine the sensitivity of the sperm. Four sets of three fertilization tests were conducted in each month. Two sets maintained a constant sperm to egg ratio of 500:1, while the other two sets utilized a sperm to egg ratio pretest to determine the ratio for optimal fertilization. Within these two treatments sperm were collected using wet and dry methods. Wet sperm collection utilized a squirt bottle to rinse gametes from the urchin, whereas the dry method consisted of collecting concentrated sperm directly from the urchin's gonopore and holding them at $4^{\circ} \mathrm{C}$. prior to exposure. In experiments conducted in March, there was higher variability in the tests using the pretest and wet sperm collection, and reduced when using dry sperm collection methods. This trend was reversed in June, 1995 (Fig. 7). Variability was greater using the dry sperm collection methods. Six tests in the June comparison demonstrated no dose-response and therefore were not included in the summary. Analysis of variance among all sperm treatments in the variability tests showed no significant differences among sensitivity because of high variability. 


\section{DISCUSSION}

An important finding of this study is that field collected urchins can be induced to spawn and produce enough gametes for toxicity testing throughout the year. In general, purple urchins demonstrate a strong seasonal trend in gamete production and are used in toxicity testing only during non-summer months (approximately October-April). Pearse (1986a) determined that photoperiod was the single most important factor in controlling gametogenesis of the purple urchin, but this study suggests that reduced water temperatures in the Monterey Bay area during spring months might affect the urchins ability to produce viable gametes for toxicity tests. Photoperiod was negatively correlated with gonadal indices of both wild and laboratory urchins, but both groups could still be induced to spawn throughout the study. Poor food quality or quantity can result in low reproductive output as food is an important requirement for gonadal growth, but field studies have demonstrated food resources have little influence on reproductive cycles (Pearse 1981). In the current study the laboratory urchins were fed consistently and the field urchins grazed on coralline algae or drift macroalgae (personal observation). Even with consistent feeding in total darkness, the laboratory urchins exhibited a reduction in gonad size during the summer months. Pearse et al. (1986a) analyzed gonadal indices four times over a 15 month study and did not note temporal differences. With food and light held constant for the laboratory group, their gonad growth may have been influenced by temperature or some undetermined internal cue.

The fluctuation of gonad size in urchins held in the dark for longer than a year suggests differences in temperature might influence gonad size, perhaps by affecting the allocation of energy between somatic and gonadal growth. Seasonal differences in sea temperature can affect gametogenesis in urchin species inhabiting environments with extreme temperature ranges (Khotimchenko 1982), but Pearse (1981) reports that this is generally untrue of purple urchins because their habitats exhibit minimal temperature 
differences. Although gonad sizes fluctuated throughout the year in the present study, the spawns still produced sufficient gametes to conduct large scale toxicity tests. Pearse (1981) attributes this condition to high gamete production and extended storage of the gametes.

Egg size remained consistent throughout this study with slight deviations occurring at the beginning and end (February 1994 and 1995). Sizes were similar to the 70-85 $\mu \mathrm{m}$ range found in previous studies (Emlet et al. 1987, Levitan 199.3). Eggs remained a consistent size even in the field group where food resources and gonad size were presumably more variable. These results agree with those of Lessios (1987) who found that temporal and spatial variability of urchin egg sizes on either side of the Panama isthmus were not affected by environmental parameters. Consistent egg size implies consistent egg quality and therefore reliable female gametes for year-round toxicity testing.

Year-round availability of spawnable animals and consistent response of the larval development test to zinc suggests that the purple urchin is a useful organism for routine toxicity testing. Bay et al. (1993) reports data from multiple tests with coefficient of variation (EC50's) ranging from $3 \%$ for salinity to $42 \%$ for copper. I found that coefficients of variation for both laboratory and field urchins animals were similar (20.8\% and $19.4 \%)$, and comparable with other ongoing urchin development tests at MPSL using copper, which have produced a coefficient of variation of $22 \%$ over a three year period ( $n=16$, personal observation). Temperature and day length had no apparent effect on the larval development tests using wild and laboratory held animals.

There was no significant difference in response to zinc among the three geographically isolated urchin groups based on three tests in March 1995, but there was a trend of increasing sensitivity with decreasing latitude. More research is needed to determine if this trend is significant. Egg size varied slightly with the San Diego urchins 
producing significantly larger eggs. Again, a difference in temperature might cause variation in the allocation of energy to eggs and gonads.

Historically, the urchin fertilization test has been widely variable in interlaboratory and intralaboratory experiments (Bay et al. 1993). Schimmel et al. (1989a) reported coefficients of variation between 16 and $60 \%$ for an intralaboratory experiment, and Gerlinger (1990) reports a coefficient of variation of $77 \%$ for an interlaboratory test among four labs in southern California. High variability in the latter may partially be attributed to the use of different urchin species and test protocols. In a study of protocol variability using purple urchins, Pastorok et al. (1994) cited a mean intralaboratory coefficient of variation of $58 \%$ and an interlaboratory coefficient of variation range of $42-98 \%$ for the reference toxicant cadmium. This variability is similar to that found in the present study, where coefficients of variation were $86.5 \%$ for laboratory and $76.8 \%$ for field urchins.

The results indicate that several aspects of the urchin fertilization protocol must be controlled for consistent results. These include sperm concentration, exposure period, reference toxicant source, dilution water, and test species (Bay et al. 1993). The present study illustrates the necessity for constant sperm concentration and suggests that sperm collection method might also play a role, although results were inconclusive.

Refinements in E.P.A. (1995) control for these factors and decrease the variability (intralaboratory $\mathrm{CV}=24 \%, \mathrm{n}=20$ ). Dilution water used during the present study was pumped continuously through the laboratory from a pristine environment. Although variation in the water chemistry might have caused variable speciation of the zinc reference toxicant, this is unlikely, as low variability was noted in the larval development test results. In addition, relatively high variability was noted in fertilization tests performed on the same day. 
Water temperature may also have contributed to variability in the fertilization test. Seasonal variability caused by temperature differences may have been important, but the data were insufficient for rigorous analysis. It is possible that the relative difference between ambient water temperature and test temperature have a significant effect on urchin gametes. EC50's in the dry sperm collection tests from March compared favorably to those during a similar period in the temporal study (Fig. 6), and June dry collection tests were similarly variable. Test temperature and field temperatures are more similar during fall and winter months. Fertilization tests conducted with a local population by an independent laboratory in southern California produce consistent results during nonsummer months, but the laboratory must switch to testing with the sand dollar, Dendraster excentricus, during the summer months as the urchins fail to spawn and the water gets warmer (Marilyn Schwartz, Ogden Environmental, San Diego, California). Another laboratory states that holding urchins at constant temperature $\left(12^{\circ} \mathrm{C}\right.$. $)$ under ambient laboratory light has resulted in consistent monthly fertilization tests with a coefficient of variation of $48.4 \%(n=31$; Patti Tenbrook, East Bay Municipal Utilities District, Oakland, California). Leahy et al. (1978) maintained female urchins in spawning condition for molecular studies by keeping culture water chilled to $11^{\circ} \mathrm{C}$. If holding urchins in the laboratory for the purposes of year round toxicity testing, it may be essential to maintain them at a constant temperature.

Another potential cause of variability in this study could have been wet sperm collection. Sea urchin sperm activate and begin to seim upon contact with water. Inconsistencies in time between spawning and the addition of sperm to the toxicant might increase the variability by allowing the sperm to become fatigued. Dry sperm collection preserves sperm viability and allows for consistent performance because different subsamples of the sperm stock are activated for density determination, sperm to egg ratio pretest, and definitive test. The utilization of a sperm to egg ratio pretest rather than a 
constant ratio might reduce variability by preventing over and underfertilization of the eggs. Dry sperm collection reduced variability during March when the urchins were in good reproductive condition, but failed to do so in June when ambient water temperatures were lower and the urchins gonads were smaller. Data from tests utilizing sperm to egg ratio pretests were inconclusive.

In examining the relative merits of any toxicity test, several things must be considered: sensitivity, logistical practicality, consistency of results, and whether or not the endpoint is ecologically relevant. Fertilization tests are generally considered more sensitive than development tests (Bay et al. 1993), but, based on the variable data produced by this study, this is inconclusive for zinc. The sensitivity of the development test to zinc was comparable to other common test species (Bay et al. 1993). Both tests involve similar preparation of the test solution and urchin gametes. The fertilization test requires less time, but the development test can be conducted successfully in only 48 hours. The development test is simpler to prepare because it does not require rigorous control of sperm concentration or sperm collection. No problems with polyspermy were encountered. Both test endpoints involve the examination of an early life history stage of the urchin and take a similar amount of time to enumerate. Fertilization tests conducted in this study produced inconsistent results compared to the development tests. Development test results were consistent through all seasons and among several populations. Both test endpoints used in this study were sublethal. The larval development test can also use survival and cytogenetic endpoints.

Though temperature, gonad size, egg size, and day length varied throughout the year, the results of the larval development tests show the purple urchin is an effective, year-round toxicity test organism. Fertilization tests have potential for year-round use, but further studies are needed to examine the effects of temperature and perhaps other 
factors on urchin gametes. I recommend that local sensitivity be evaluated in any area where urchins are collected for testing. 


\section{REFERENCES}

Anderson, B.S., J.W. Hunt, M. Hester, B.M. Phillips. 199X (in press). Assessment of sediment toxicity at the sediment-water interface. In: Techniques in Aquatic Toxicology. G.K. Ostrander, Ed., Lewis publishers/CRC Press, Boca Raton, Florida. Ankley, G.T., M.K. Schubauer-Berigan, and J.R. Dierkes. 1991. Predicting the toxicity of bulk sediments to aquatic organisms with aqueous test fraction: Pore water vs. elutriate. Environ. Toxicol. Chem. 10:1356-1366.

American Society of Testing and Materials (ASTM). 1995. Standard guide for conducting static acute toxicity tests with echinoid embryos. ASTM E 1563-95. In ASTM 11.05 Annual Book of Standards. ASTM, Philadelphia, PA. pp. 1029-1047.

Bay, S.M., R.M. Burgess, and D. Nacci. 1993. Status and applications of echinoid (phylum Echinodermata) toxicity test methods. Environmental Toxicology and Risk Assessment, ASTM STP 1179, Landis, W.G., Hughes, J.S., and Lewis, M.A., Eds., American Society for Testing and Materials, Philadelphia, pp. 281-302.

Burgess, R.M., K.A. Schweitzer, R. McKinney, and , D.K. Phelps. 1993. Contaminated marine sediments: water column and interstitial water toxic effects. Environ. Toxicol. Chem. 12:127-138.

Carr, R.S. and D.C. Chapman. 1990. Comparison of solid phase and pore water approaches for assessing the quality of estuarine sediments. Chemistry and Ecology. $7: 19-30$.

Dinnel, P.A., J.M. Link, and Q.J. Stober. 1987. Improved methodology for a sea urchin sperm cell bioassay for marine waters. Arch. Environ. Contam. Toxicol. 16:23-32.

Dinnel, P. A., G.G. Pagano, and P.S. Oshida. 1988. A Sea Urchin Test System for Environmental Monitoring. In: Echinoderm Biology. Burke, R.D., Mladenov, P.V., Lambert, P., and Parsley, R.L., Eds., A.A. Balkema, Rotterdam, The Netherlands. pp. 611-619. 
Dinnel, P.A., J.M. Link, Q.J. Stober, Letourneau, and W.E. Roberts. 1989. Comparative sensitivity of sea urchin sperm bioassays to metals and pesticides. Arch. Environ Contam Toxicol. 18:748-755.

Emlet, R.B., L.R. McEdward, and R.R. Strathmann. 1987. Echinoderm larval ecology viewed from the egg. In: Echinoderm studies, Vol. 2, Jangoux, M. and Lawrence, J.M., Eds., A.A. Balkema, Rotterdam, The Netherlands. pp. 55-137.

E.P.A. 199X (in press). Short-term methods for estimating the chronic toxicity of effluents and recieveing waters to west coast marine and estuarine organisms. Chapman, G.A., Denton, D.L., and Lazorchak, J.M. (Eds.). E.P.A./600/R-95-136. U.S.E.P.A. Cincinnati, OH. 692 pp.

Gerlinger, T.V. 1990. Preliminary toxicity study final effluent January-April, 1990. County Sanitation Districts of Orange County. $109 \mathrm{pp}$.

Gonor, J.J. 1972. Gonad growth in the sea urchin, Strongylocentrotus purpuratus (Stimpson) (Echinodermata: Echinoidea) and the assumptions of gonad index methods. J. Exp. Mar. Biol. Ecol. 10:89-103.

Hamilton, M.A., R.C. Russo, and R.V. Thurston. 1977. Trimmed Spearman-Karber method for estimating median lethal concentrations in toxicity bioassays. Environ. Sci. Technol.. 11:714-719.

Hose, J.E. 1985. Potential uses of sea urchin embryos for identifying toxic chemicals: description of a bioassay incorporating cytologic, cytogenetic and embryologic endpoints. J. Applied Toxicol. 5:245-254.

Khotimchenko, Y.S. 1982. Effect of noradrenalin, dopamine and adrenolytics on growth and maturation of the sea urchin, Strongylocentrotus nudus Agassiz. Inter. J. Invert. Reprod. 4:369-373.

Kobayashi, N. 1972. Marine pollution bioassay by using sea urchin eggs in the Inland Sea of Japan. Publ. Seto Mar. Biol. Lab. 19:359-381. 
Leahy, P.S., T.C. Tutschulte, R.J. Britten, and E.H. Davidson. 1978. Large-scale laboratory maintenance system for gravid purple sea urchins (Strongylocentrotus purpuratus). J. Exp. Zool. 204:369-380.

Lessios, H.A. 1987. Temporal and spatial variation in egg size of 13 Panamanian echinoids. J. Exp. Mar. Biol. Ecol. 114:217-239.

Levitan, D.R. 1993. The importance of sperm limitation to the evolution of egg size in marine invertebrates. Am. Nat. 141:517-536.

Long, E.R., M.F. Buchman, S.M. Bay, R.J. Breteler, R.S. Carr, P.M. Chapman, J.E. Hose, A.L. Lissner, J. Scott, and D.A. Wolfe. 1990. Comparative evaluation of five toxicity tests with sediments from San Francisco and Tomales Bay, California. Environ. Toxicol. Chem. 9:1193-1214.

Meador, J.P., B.D. Ross, P.A. Dinnel, and S.J. Picquelle. 1990. An analysis of the relationship between a sand-dollar embryo elutriate assay and sediment contaminants from stations in an urban embayment of Puget Sound, Washington. Mar. Environ. Res. 30:251-272.

Milliken, G.A. and D.E. Johnson. 1984. Analysis of Messy Data, Volume 1: Designed Experiments. Van Nostrand Reinhold, New York. 473 pp.

Mitsunaga, K. and I. Yasumasu. 1984. Stage specific effects of $\mathrm{Zn}^{+2}$ on sea urchin embryogenesis. Dev. Growth and Differ. 26:317-327.

Morris, R.H., D.P. Abbott, and E.C. Haderlie. 1980. Intertidal invertebrates of California. Stanford University Press, California. $690 \mathrm{pp}$.

Nacci, D., P. Comeleo, E. Petrocelli, A. Kuhn-Hines, G. Modica, and G. Morrison. 1991. Performance evaluation of sperm cell toxicity test using the sea urchin, Arbacia punctulata. In: Aquatic Toxicology and Risk Assessment: 14th Volume. Mayes, M.A., Barron, M.G., Eds. American Society for Testing and Materials, Philadelphia, Pennsylvania. pp. 324-336. 
Oshida, P.S., T.K. Goochey, and A.J. Mearns. 1981. Effects of municipal wastewater on fertilization, survival, and development of the sea urchin, Strongylocentrotus purpuratus. In: Biological Monitoring of Marine Pollutants. Vernberg, F.J., Calabrese, A., Therberg, F.P., and Vernberg, W.B. Eds. Academic Press, New York. pp. 389-403

Pastorok, R.A., J.W. Anderson, M.K. Butcher, and J.E. Sexton 1994. West coast marine species chronic protocol variability study. Prepared for the Washington Department of Ecology by PTI Environmental Services, Bellevue, Washington.

Pearse, J.S. 1981. Synchronization of gametogenesis in the sea urchins Strongylocentrotus purpuratus and S. Franciscanus. In Advances in invertebrate reproduction, Clark, W.H., Jr. and Adams, T.S. Eds. Elsevier, Amsterdam. pp. 53-68.

Pearse, J.S., V.B. Pearse, and K.K. Davis. 1986a. Photoperiodic regulation of gametogenesis and growth in the sea urchin Strongylocentrotus purpuratus. $J$. Exp. Zool. 237:107-118.

Pearse, J.S. and A.H. Hines. 1987. Long-term population dynamics of sea urchins in a central California kelp forest: rare recruitment and rapid decline. Mar. Ecol. Prog. Ser. 39:275-283.

Rulon, O. 1957. Developmental modifications in the sand dollar caused by cobaltous chloride in combination with sodium selenite and zinc chloride. Biol. Bull. 113: 480-487.

Sano, K. and H. Mohri. 1976. Fertilization of sea urchins needs magnesium ions in sea water. Science. 192:1339-1340.

Schafer, H.A. 1990. Characteristics of effluents from large municipal wastewater treatment plants in 1989. In: Southern California Coastal Water Research Project 
Annual Report, 1989-1990. J.N. Cross and D.M. Wiley (Eds.). Southern California Coastal Water Research Project, Long Beach, California. pp. 8-15. Schimmel, S.C., G.E. Morrison, and M.A. Heber. 1989a. Marine complex effluent toxicity program: test sensitivity, repeatability and relevance to receiving water toxicity. Environ. Toxicol. Chem. 8:739-746.

Viarengo, A. 1985. Biochemical effects of trace metals. Mar. Poll. Bull. 16:153-158.

Zar, J.H. 1984. Biostatistical Analysis. Prentice-Hall, Inc., Englewood Cliffs, NJ. 718 pp. 

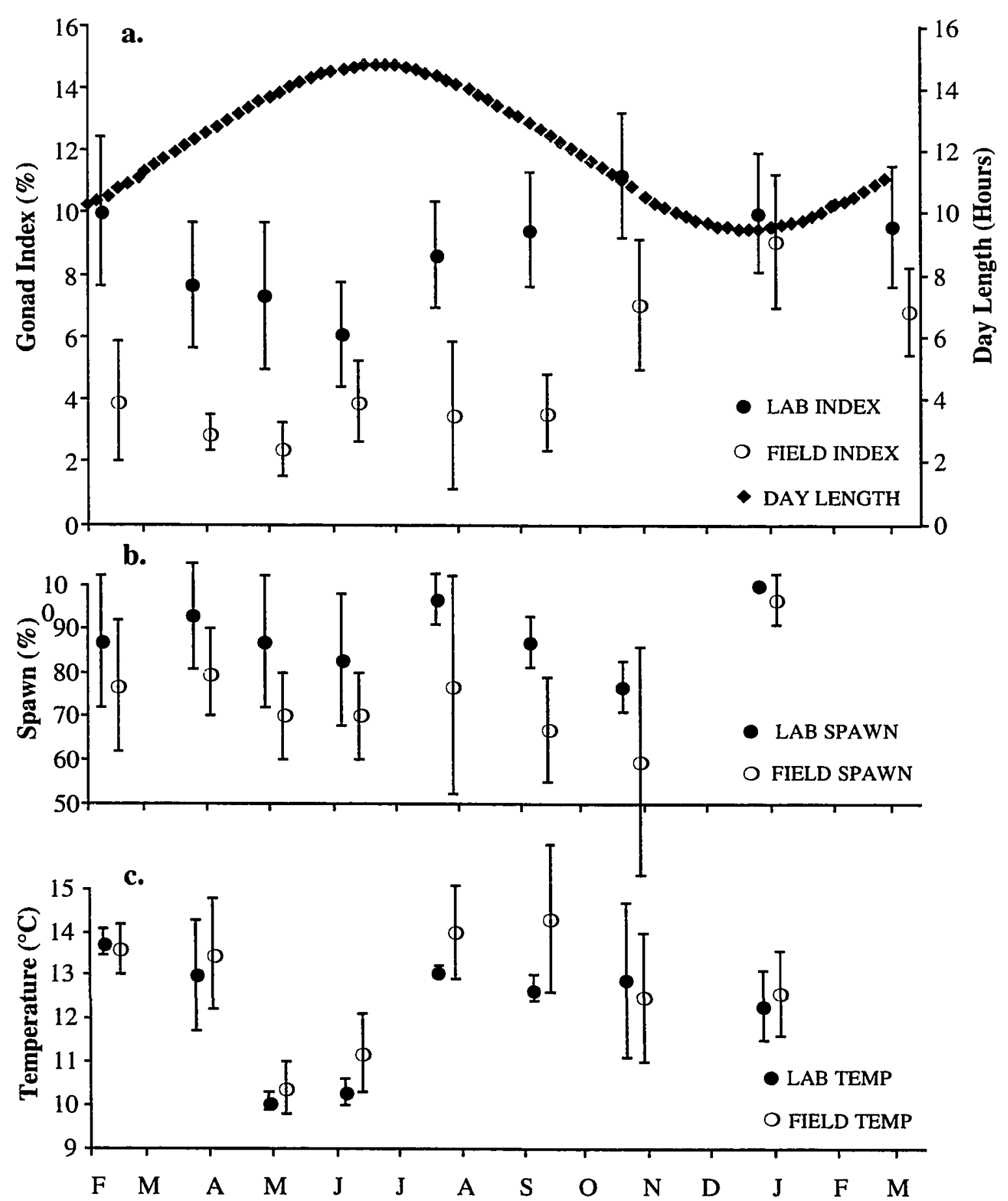

Figure 1. a) Day length plotted with gonad indices for laboratory and field collected urchins ( $n=10$ gonads). b) Mean percent of urchins spawning for each test period ( $n=3$ tests). c) Mean laboratory and field temperatures at the time of urchin collection $(n=3)$. Error bars indicate one standard deviation. 


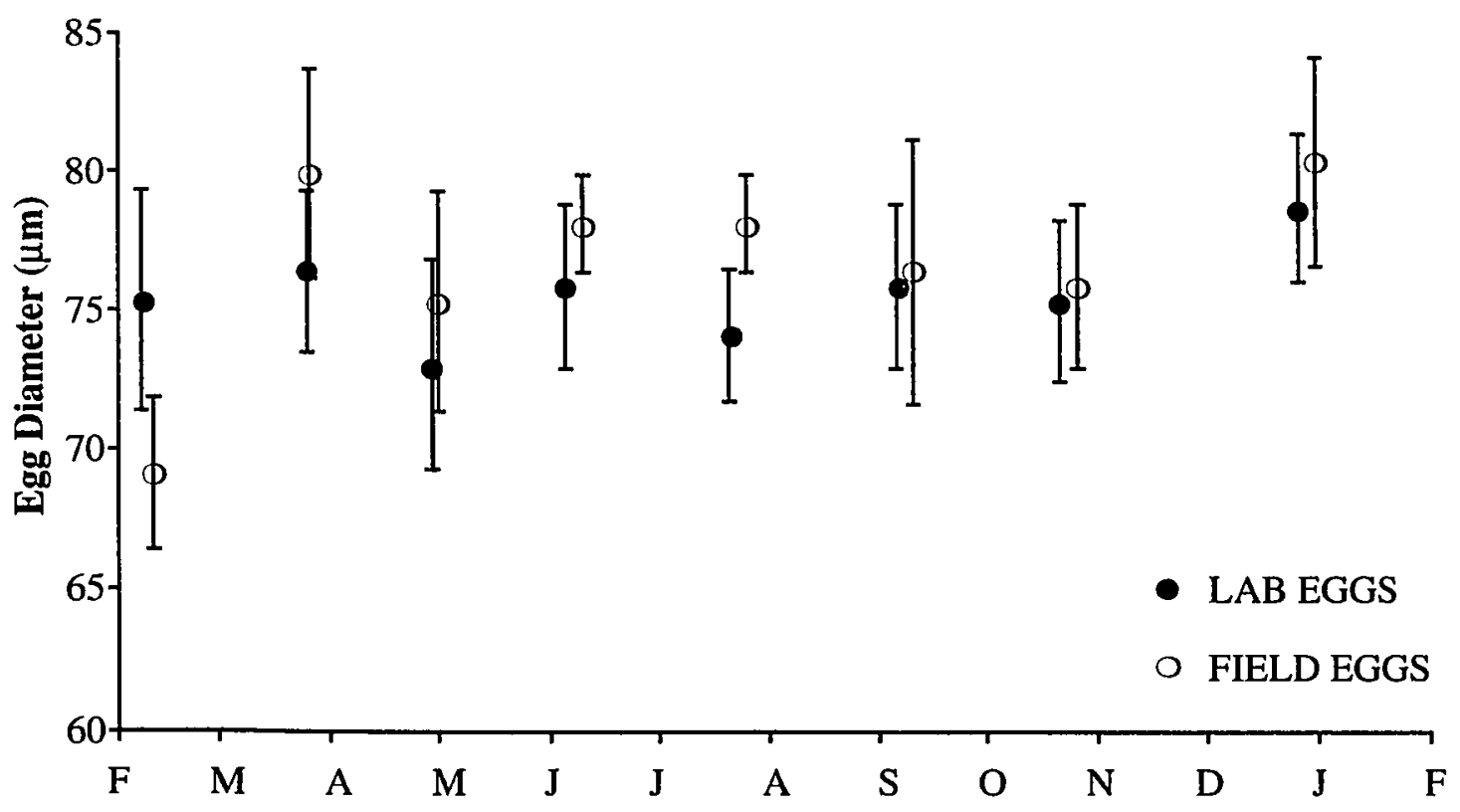

Figure 2. Mean egg diameter for laboratory and field collected urchins ( $\mathrm{n}=10$ eggs, error bars indicate one standard deviation). 


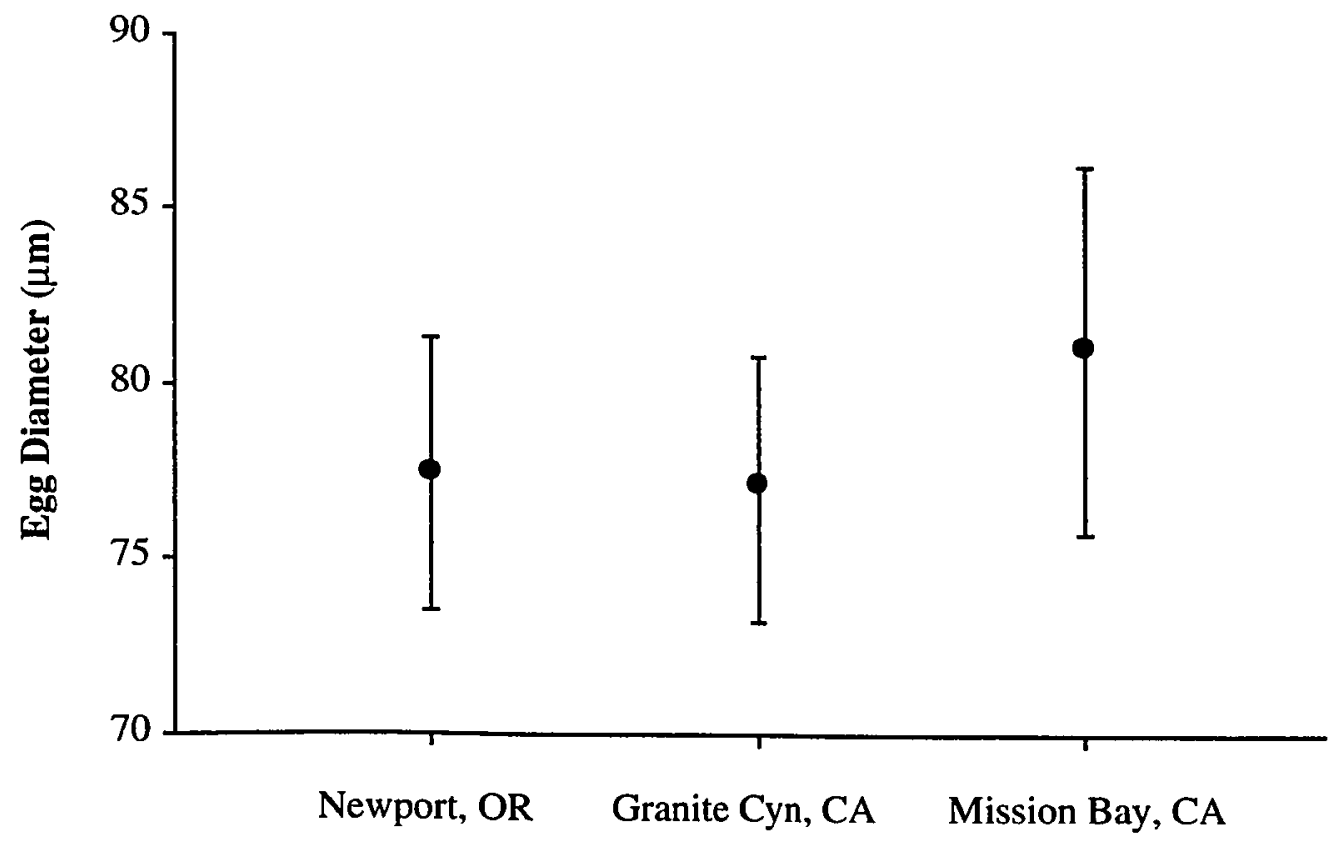

Figure 3. Mean egg diameter for three geographic locations ( $n=30$ eggs, error bars indicate one standard deviation). 


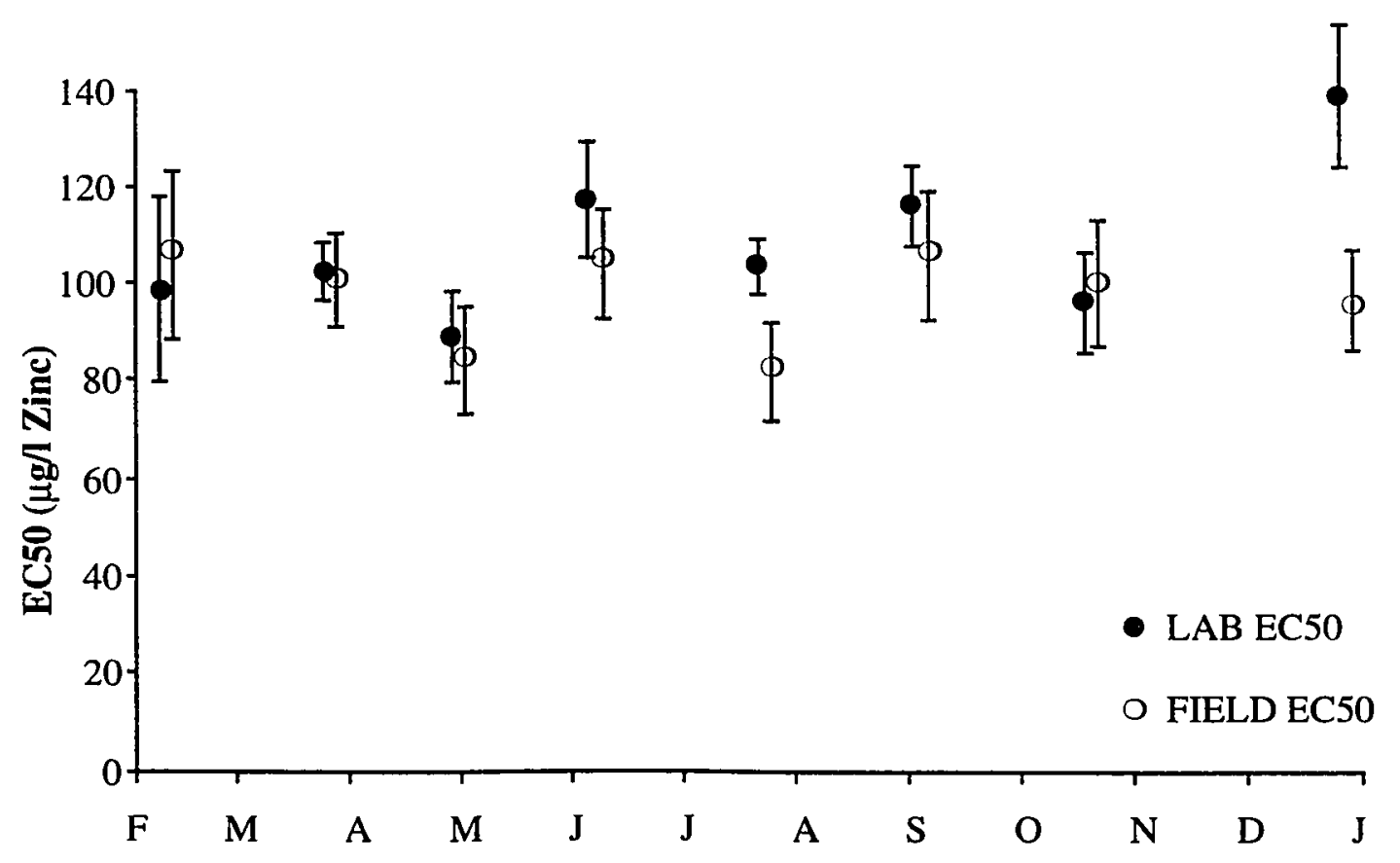

Figure 4. Mean EC50 from larval development tests performed on laboratory maintained and field collected urchins $(n=3$ tests, error bars indicate one standard error). 


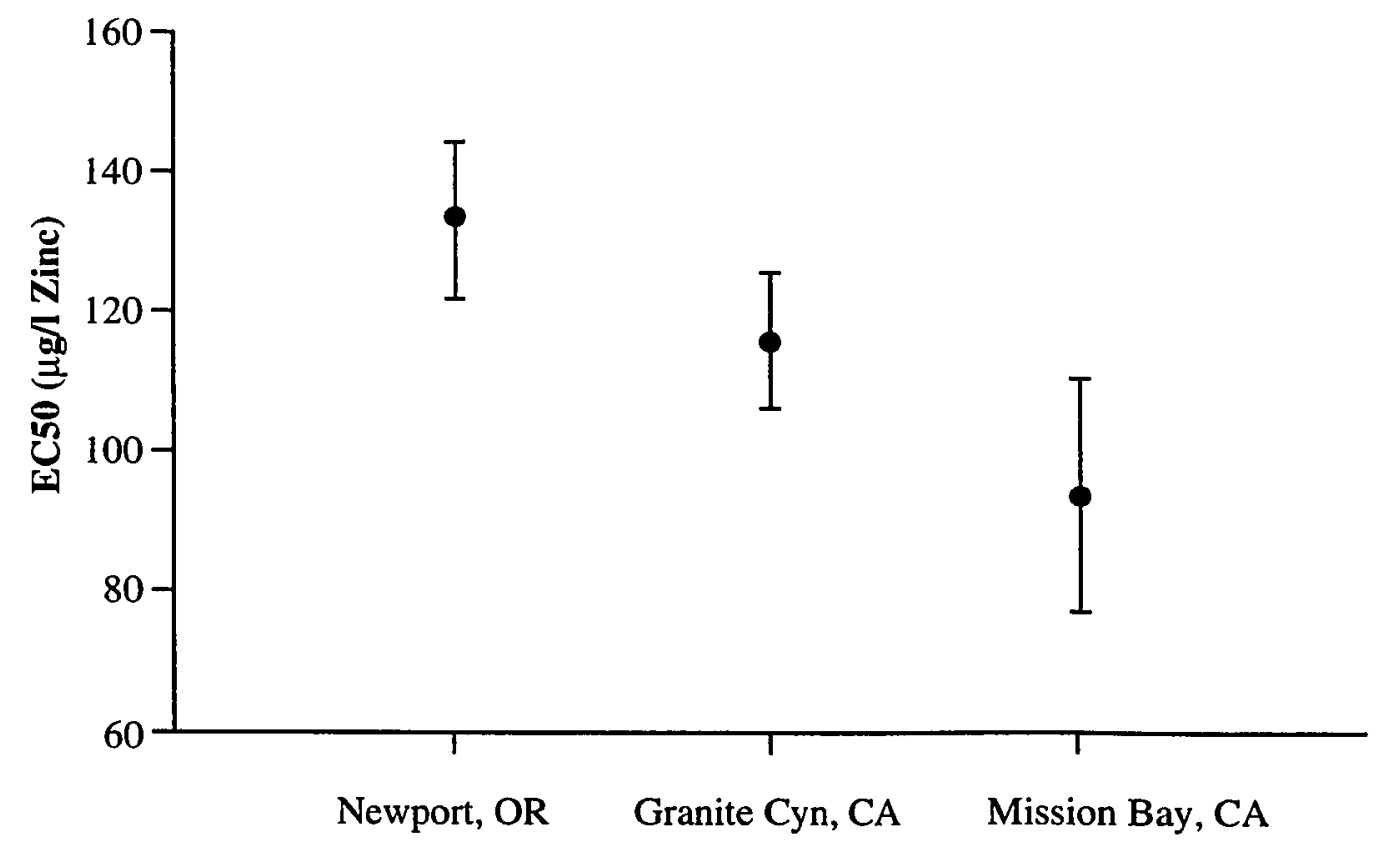

Figure 5. Mean EC50 from larval development tests with urchins from three geographically isolated locations ( $n=3$ tests per population, error bars indicate one standard error). 


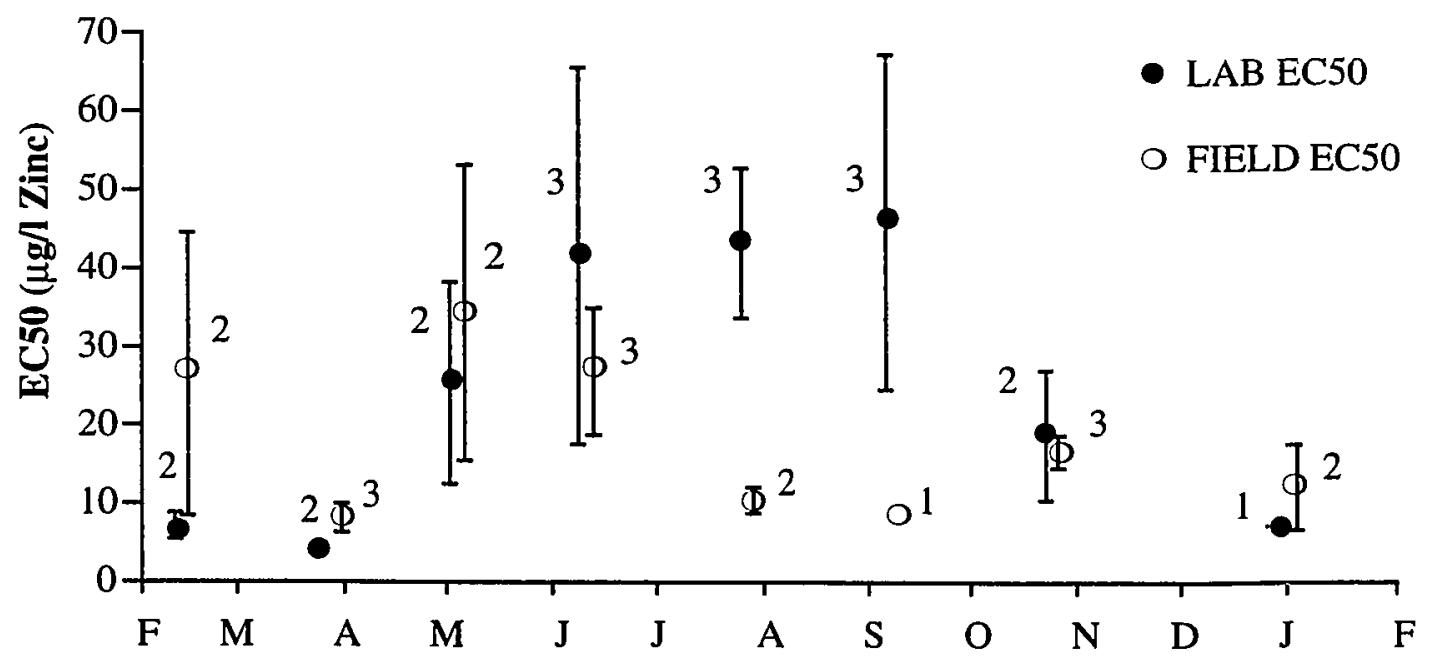

Figure 6. Mean EC50 from fertilization tests performed on laboratory maintained and field collected urchins ( $n$ 's are indicated by numbers, error bars indicate standard error). 

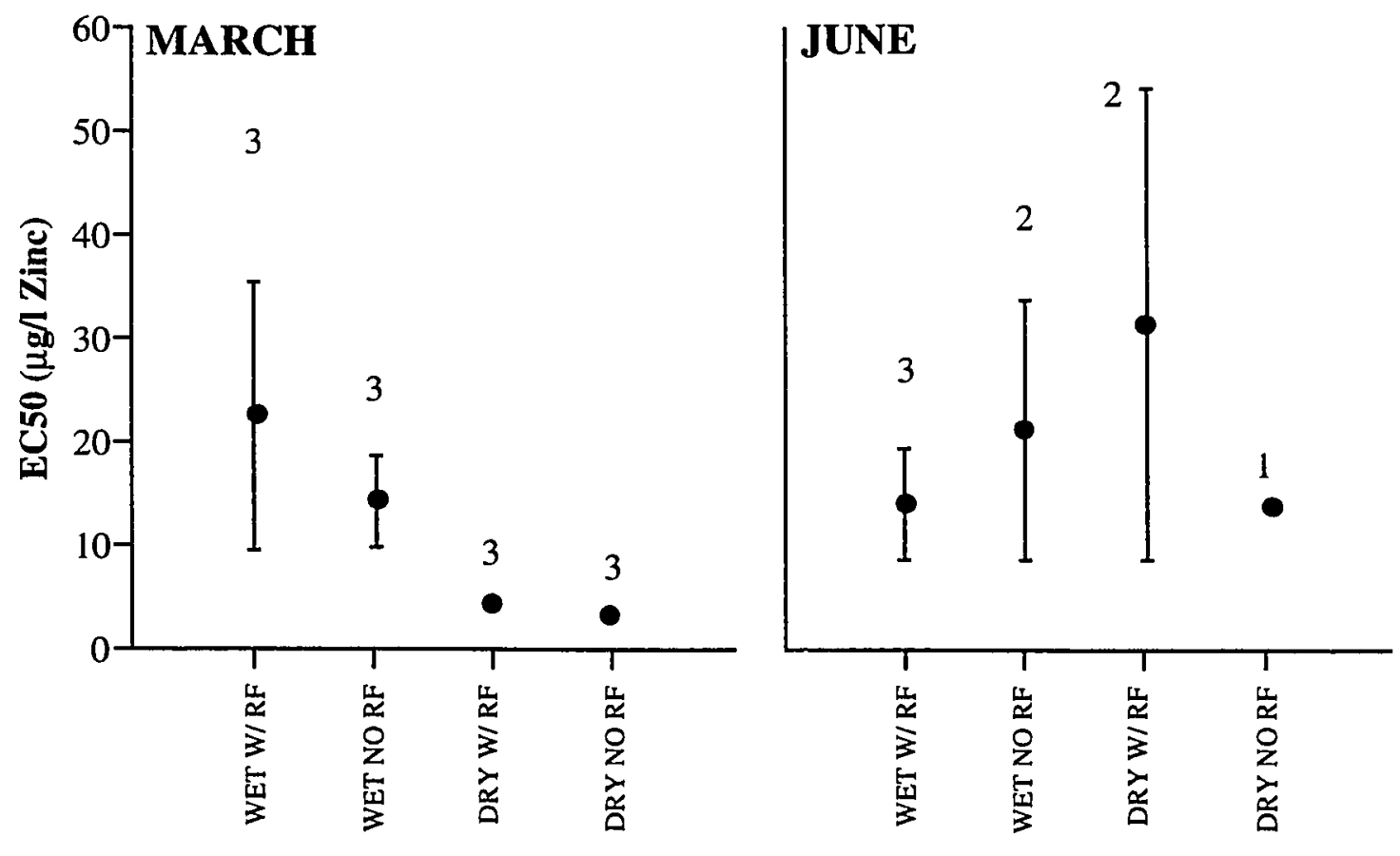

Figure. 7. Mean EC50's from fertilization tests comparing sperm collection methods and sperm to egg ratios (n's are indicated by number, error bars indicate standard error). Treatments are wet sperm collection with and without a sperm to egg ratio rangefinder pretest (RF), and dry sperm collection with and without a pretest. 